streaking and slightly increased the number of visible spots (Figure 2). This observation is consistent with another report that suggests that additional precipitations/washes reduce sample impurities, allowing for subsequent isoelectric focusing to achieve greater separation of proteins in the first dimension, with an increased overall resolution of proteins on two-dimensional gels (7). Additional TCA precipitations limited streaking between 81-97 kDa but were accompanied by spots of less intensity. Washing of samples using ammonium bicarbonate and acetone were also tested. Although these additional washing steps considerably reduced streaking, the total number of protein spots significantly decreased. Therefore, these steps were not incorporated into our final protocol.

In conclusion, we have developed an improved protein isolation protocol for $H$. volcanii that can be used successfully for 2D-PAGE. One major advantage of this method is that it is compatible with the global identification of proteins using MALDI-TOF MS because proteins are not labeled. Significantly more protein spots were noted at the stationary phase versus the mid-log phase. Additional TCA washes during sample preparation improved the spot resolution and decreased streaking on the gels, which, in turn, resulted in enhanced spot detection. The future analysis of the $H$. volcanii proteome may yield valuable information about the organism's ability to tolerate and survive extremely high salt conditions. In addition, this procedure may prove useful for the proteomic analyses of other halophiles.

\section{ACKNOWLEDGMENTS}

This work was supported by grant no. DE-FG02-98ER62592 from the US Department of Energy to V.G.D.

\section{REFERENCES}

1.Fichmann, J. and R. Westermeier. 1999. 2D protein gel electrophoresis, p. 1-7. In A.J. Link (Ed.), 2-D Proteome Analysis Protocols: An Overview, Methods in Molecular Biology, vol. 112. Humana Press, Totowa, NJ.

2.Mojica F.J.M., E. Cisneros, C. Ferrer, F. Rodriguez-Valera, and G. Juez. 1997.
Osmotically induced response in representatives of halophilic prokaryotes: the bacterium Halomonas elongata and the archaeon Haloferax volcanii. Am. Sci. Microbiol. 179: 5471-5481.

3.Bradford, M.M. 1976. A rapid and sensitive method for quantitation of microgram quantities of protein utilizing the principle of protein-dye binding. Anal. Biochem. 72: 248-254.

4.Rafie-Kolpin, M., R.C. Essenburg, and J.H. Wyckoff. 1996. Identification and comparison of macrophage-induced proteins and proteins induced under various stress conditions in Brucella abortus. Infect. Immun. 64: 5274-5283.

5.Wagner, M.A., M. Eschenbrenner, T.A. Horn, J.A. Kraycer, C.V. Mujer, S. Hagius, P. Elzer, and V.G. DelVecchio. 2002. Global analysis of the Brucella melitensis proteome: identification of proteins expressed in laboratory grown culture. Proteomics 2:1047-1060.

6.Eschenbrenner, M., M.A. Wagner, T.A.
Horn, J.A. Kraycer, C.V. Mujer, S. Hagius, P. Elzer, and V.G. DelVecchio. 2002. Comparative proteome analysis of Brucella melitensis vaccine strain Rev 1 and virulent strain, 16M. J. Bacteriol. 184:4962-4970.

7.Janson, J.C. and L. Ryden. 1998. Isoelectric focusing, p. 495-528. In J.-C. Janson and L. Ryden (Eds.), Protein Purification: Principles, High Resolution Methods, and Applications. John Wiley and Sons, New York.

Received 17 April 2003; accepted 12 June 2003.

Address correspondence to Vito G. DelVecchio, Institute of Molecular Biology and Medicine, The University of Scranton, 800 Linden Street, Scranton, PA 18510, USA. e-mail:vimbm@aol.com

\title{
Rapid selection of Drosophila S2 cells with the puromycin resistance gene
}

Takayuki Iwaki, Mariana Figuera, Victoria A. Ploplis, and Francis J. Castellino University of Notre Dame, Notre Dame, IN, USA

BioTechniques 35:482-486 (September 2003)

The Drosophila melanogaster Schneider 2 (S2) cell line was established in 1972 (1). These cells grow rapidly in culture at room temperature without a need for $\mathrm{CO}_{2}$. Various expression vectors have been constructed that facilitate both constitutive (2) and inducible expression (3). Many studies have indicated that the generation of recombinant proteins with $\mathrm{S} 2$ cells is more desirable than other methods, since native proteins derived from S2 cells do not usually interact with those derived from mammalian cells. Despite these advantages, only two markers (i.e., hygromycin and blastcidin) are commercially available for establishing stable transformants (Invitrogen, Carlsbad, CA, USA). Additionally, approximately 2 weeks are required to establish a stable transformant with blastcidin, and more than 3 weeks are needed with hygromycin.

Figure 1 illustrates the structure of a co-expression vector for $\mathrm{S} 2$ cells, $\mathrm{pCo}-$ PURO, which contains the Copia pro- moter, puromycin $\mathrm{N}$-acetyl-transferase (pac), and the simian virus 40 (SV40) poly(A) sequence. The cDNA coding for the pac sequence was digested from the puromycin resistance module (Stratagene, La Jolla, CA, USA) with restriction enzymes HindIII and $\mathrm{XbaI}$ (both from Promega, Madison, WI, USA). This pac sequence was blunted with T4 polymerase (Promega) and ligated with T4 ligase (Promega) to the EcoRV site of pBSIISK+ (Stratagene). After determination of the correct orientation of the insert with several restriction digestions, the pac sequence in pBSIISK + was digested with BamHI and $\mathrm{XhoI}$ (both from Promega) (Figure 1, Fragment 2). The plasmid, pCoHYGRO, which contains the Copia promoter, the hygromycin resistance gene, and the SV40 poly(A) sequence (Invitrogen) was digested with $\mathrm{XbaI}$ and $\mathrm{XhoI}$ to remove the Copia promoter and the hygromycin resistance gene (Figure 1, Backbone 1).

The sequence of the Copia promoter 
was obtained by PCR using forward (F) and reverse (R) primers: CopiaF 5'-CAGGTCGACTCTAGAGGATC-3' and CopiaR 5'-GAAGATCTGTTGTAATTTATAATTTATATTTCC-3'.

The PCR product (364 bp) was digested with $\mathrm{XbaI}$ and $\mathrm{BglII}$ (Promega) (Figure 1, Fragment 1). Fragments 1 and 2 were ligated to Backbone 1, and pCoPURO was obtained (Figure 1).

Nontransfected S2 cells (Invitrogen) were maintained at $25^{\circ} \mathrm{C}$ in Drosophila Schneider medium (Invitrogen) supplemented with $10 \%$ fetal bovine serum (FBS), $100 \mathrm{U} / \mathrm{mL}$ penicillin G-Na salt, $0.2 \mathrm{mg} / \mathrm{mL}$ streptomycin sulfate, and $0.5 \mu \mathrm{g} / \mathrm{mL}$ amphotericin B (the last three items from ICN Biomedicals, Aurora, OH, USA) (complete media). $\mathrm{S} 2$ cells $\left(6 \times 10^{5}\right)$ were seeded to each well of a 24-well plate containing $600 \mu \mathrm{L}$ complete media. A calcium phosphate transfection procedure was employed to produce stable transformants. The calcium phosphate-DNA precipitate was incubated with the cells for $16 \mathrm{~h}$, after which the cells were pelleted gently for $2 \mathrm{~min}$ at $800 \times g$ and resuspended in 600 $\mu \mathrm{L}$ complete media. Washing was repeated twice before the cells were replated into the original 24-well plate. After $24 \mathrm{~h}$, the cells were repelleted as before and resuspended in $600 \mu \mathrm{L}$ complete media containing puromycin at a final concentration of 2-10 $\mu \mathrm{g} / \mathrm{mL}$. After selection, cells in the 24-well plate were transferred to a 6 well plate with $3 \mathrm{~mL}$ media with fetal calf serum (FCS) and puromycin, and 3 days later, the cells were transferred to a $25-\mathrm{cm}^{2}$ flask with $5 \mathrm{~mL}$ media containing FCS and puromycin. After an additional 3 days, the cells were transferred to a $75-\mathrm{cm}^{2}$ flask with 15 $\mathrm{mL}$ fresh media and then transferred after 3 days to $3 \times 150-\mathrm{cm}^{2}$ flasks with $30 \mathrm{~mL}$ of the same media. After an appropriate time (approximately 3 days), the cells were transferred to a spinner flask with $200 \mathrm{~mL}$ media (without FCS and puromycin). The next day, additional media $(800 \mathrm{~mL})$ containing $625 \mu \mathrm{M} \mathrm{CuSO}_{4}$ were added, and 4 days later, the supernatant was collected. All of these steps, after selection, are similar regardless of the marker used, and the great advantage of the puromycin selection is the speed of the selection process.

Figure 2 presents the survival curve of $\mathrm{S} 2$ cells, without pCoPURO transfection, at various concentrations of puromycin. Nontransfected S2 cells were eliminated within 4 days at a concentration of $2 \mu \mathrm{g} / \mathrm{mL}$ of puromycin, and this process was accelerated at higher concentrations. In contrast, S2 cells, cotransfected with pCoPURO, were capable of growth at $2-10 \mu \mathrm{g} / \mathrm{mL}$ of puromycin (data not shown).

After obtaining these results, a stable transformant that expressed a plasminogen $(\mathrm{Pg})$ protein fragment was constructed. This Pg polypeptide lacks the catalytic domain and consists of the activation peptide (AP) and, proceeding downstream, the kringle $(\mathrm{K}) 5$ region of the protein (AP-K5). The plasmid, $\mathrm{pMT/BiP/[AP-K5],} \mathrm{was} \mathrm{used} \mathrm{as} \mathrm{the}$ expression vector for AP-K5. pMT/ $\mathrm{BiP} /[\mathrm{AP}-\mathrm{K} 5](4.8 \mu \mathrm{g})$ was transfected into $\mathrm{S} 2$ cells with $0.2 \mu \mathrm{g}$ of $\mathrm{pCoPURO}$ or pCoHYGRO. The transfections were carried out as described above with 6 $\mu \mathrm{g} / \mathrm{mL}$ of puromycin for pCoPURO and $250 \mu \mathrm{g} / \mathrm{mL}$ of hygromycin for pCoHYGRO. Stable transformants were obtained in 3 days with pCoPURO and in 3 weeks with pCoHYGRO. Stably transformed $\mathrm{S} 2$ cells $\left(1.0 \times 10^{7}\right)$ were seeded onto a 6-well plate containing $3 \mathrm{~mL}$ of incomplete medium. After 16 h, $15 \mu \mathrm{L}$ of $100 \mathrm{mM} \mathrm{CuSO}_{4}$ (final concentration $500 \mu \mathrm{M}$ ) were added to each well. The culture media supernatant was collected $96 \mathrm{~h}$ later. An aliquot of $15 \mu \mathrm{L}$ culture media supernatant was subjected to electrophoresis $[10 \%$ sodium dodecyl sulfate polyacrylamide gel electrophoresis (SDS-PAGE)] and transferred onto a polyvinylidene 


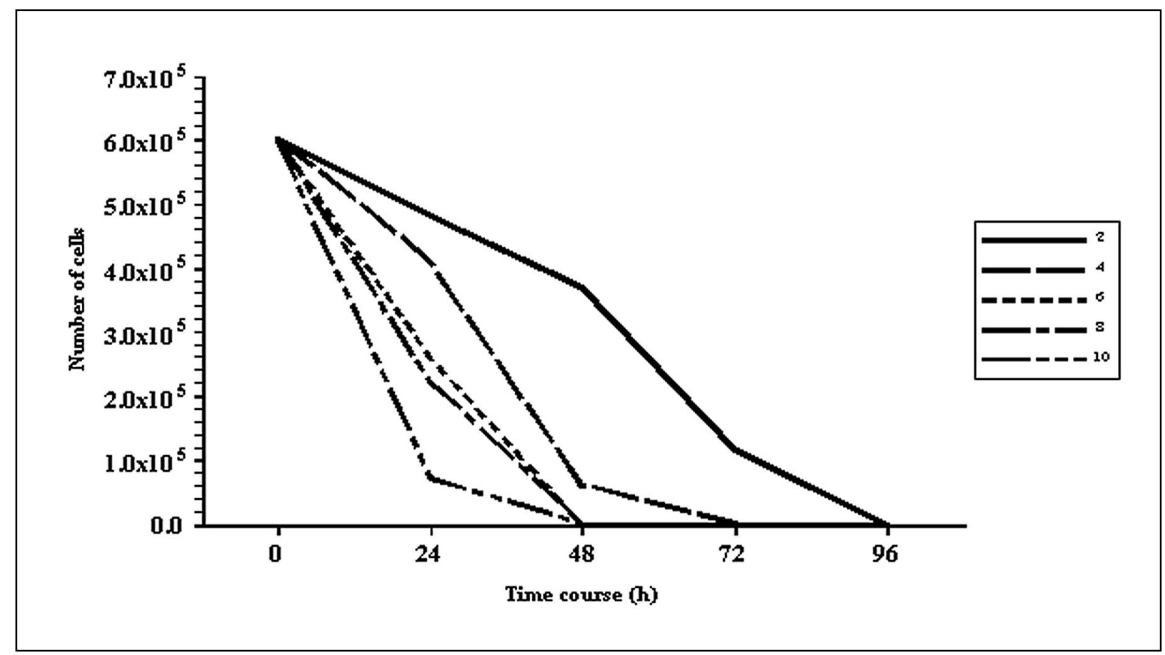

Figure 2. The effect of various puromycin concentrations in selection of transfected S2 cells. The numbers $2-10$ in the right column indicate the concentration $(\mu \mathrm{g} / \mathrm{mL})$ of puromycin used to apply selection pressure. Shown are the averages from four replicates.

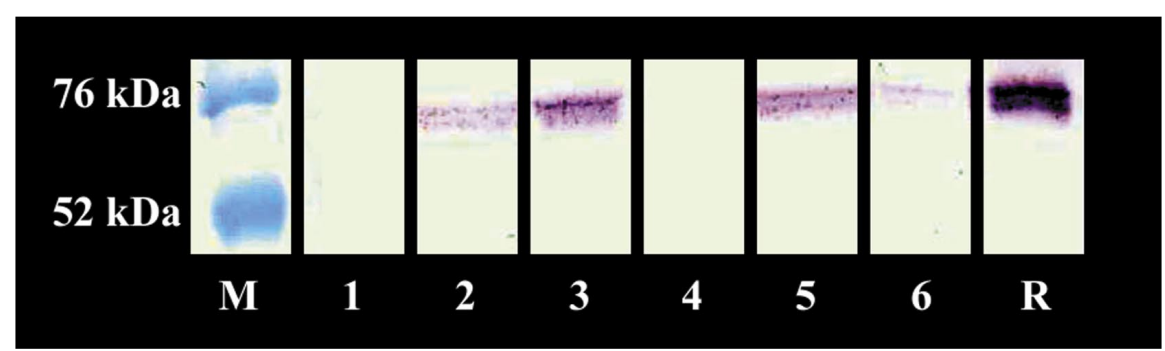

Figure 3. Western blot analysis of r[AP-K5]. M indicates the marker mixture. Lanes 1 and 4 represent supernatants with puromycin selection without induction. Lanes 2 and 5 represent supernatants with puromycin selection and induction. Lanes 3 and 6 represent supernatant with hygromycin selection and induction. $\mathrm{R}$ indicates the recombinant $\mathrm{hPg}$ protein fragment.

fluoride (PVDF) membrane (Amersham Biosciences, Piscataway, NJ, USA). The membrane was blocked with $2 \%$ nonfat dry milk in Tris-buffered saline and $0.05 \%$ Tween $^{\circledR} 20$ (TBST), pH 8.0, for $1 \mathrm{~h}$ at room temperature. The membrane was then probed with rabbit-anti-hPg polyclonal antibodies (generated in our laboratory) for $1 \mathrm{~h}$ at room temperature. After washing the membrane three times with $10 \mathrm{~mL}$ TBST for $5 \mathrm{~min}$, the membrane was incubated with alkaline phosphatase-conjugated goat-anti-rabbit immunoglobulin $\mathrm{G}(\mathrm{IgG})$ (Southern Biotechnology Associates, Birmingham, AL, USA) for $1 \mathrm{~h}$ at room temperature. After washing three times as above, the membrane was visualized with the chromogen, nitroblue tetrazolium/5-bromo4-chloro-3-indolyl-phosphate (BCIP) (Sigma, St. Louis, MO, USA). Figure 3 shows that the expression of AP-K5, utilizing pCoPURO, was equivalent to that with $\mathrm{pCoHYGRO}$. There was no protein identified in the supernatant without induction. After induction, the protein was detected in the supernatants from both the hygromycin and puromycin selections. After purification of AP-K5, further analyses indicated that yields of 4-8 mg/L were obtained utilizing either strategy, dependent on the individual clones tested.

While the Drosophila expression system has several advantages over other methods, commercially available selection markers are limited. The selection marker plasmids, pCoBLAST and pCoHYGRO, require long selection times ( 2 and 3 weeks, respectively). In order to minimize the time for selection, the co-expression vector, pCoPURO, was constructed. The Copia promoter accelerates the expression of the downstream DNA. The pac gene has been used successfully as a dominant selectable marker gene in a variety of mammalian cells lines $(4,5)$ and in insect cells (6). However, there is no report of the pac gene being transferred into S2 cells. This vector efficiently transfected S2 cells and provided antibiotic resistance to the cells. This system allows a more rapid expression to be obtained. In the example provided here, expression occurred in 3 days, and the yield of recombinant protein generated with this plasmid was similar to that with other established selection procedures.

\section{ACKNOWLEDGMENTS}

This work was supported by $\mathrm{Na}$ tional Institutes of Health $(\mathrm{NIH})$ grants HL-13423 (to F.J.C.) and HL-63682 (to V.A.P.) and by the Kleiderer-Pezold Family Endowed Professorship (to F.J.C.), the Walther Cancer Institute (to T.I.), and the W.M. Keck Center for Transgene Research.

\section{REFERENCES}

1.Schneider, I. 1972. Cell lines derived from late embryonic stage of Drosophila melanogaster. Embryol. Exp. Morph. 27:363-365.

2.Hill, R.M., S.O. Brennan, and N.P. Birch. 2001. Expression, purification, and functional characterization of the serine protease inhibitor neuroserpin expressed in Drosophila S2 cells. Protein Exp. Purification 22:406-413.

3.Nilsen, S.L. and F.J. Castellino. 1999. Expression of human plasminogen in Drosophila S2 cells. Protein Exp. Purification 16:136-143.

4.Gomez Lahoz, E., M.S. Lopez de Haro, P. Esponda, and A. Nieto. 1992. Use of puromycin $\mathrm{N}$-acetyltransferase $(P A C)$ as a new reporter gene in transgenic animals. Nucleic Acids Res. 19:3465.

5.Vara, J.A., A. Portela, J. Ortin, and A. Jimenez. 1986. Expression in mammalian cells of a gene from Streptomyces alboniger conferring puromycin resistance. Nucleic Acids Res. 14:4617-4624.

6.McLachlin, J.R. and L.K. Miller. 1997. Stable transformation of insect cells to coexpress a rapidly selectable marker gene and an inhibitor of apoptosis. In Vitro Cell Dev. Biol. Anim. 33:575-579.

Received 24 April 2003; accepted 12 June 2003.

Address correspondence to Takayuki Iwaki, Department of Chemistry and Biochemistry, University of Notre Dame, Notre Dame, IN 46556,USA.e-mail: tiwaki@nd.edu 